\title{
ANALISIS PENGARUH BAURAN PEMASARAN (MARKETING $M I X$ 7-P) TERHADAP KEPUTUSAN PEMBELIAN DI THIWUL AYU MBOK SUM
}

\section{The Effect Analysis Of Marketing Mix (7P) On Purchase Decision In Thiwul Ayu Mbok Sum}

\author{
Lilik Andriyanto, Siti Syamsiar, Indah Widowati* \\ Program Studi Agribisnis, Fakultas Pertanian, \\ Universitas Pembangunan Nasional "Veteran" Yogyakarta \\ Jl. Padjajaran (Lingkar Utara 104) Condongcatur, Yogyakarta, 55283, Indonesia \\ email korespondensi: widowati2010@gmail.com
}

Diterima tanggal : 20 Januari 2019 ; Disetujui tanggal : 21 April 2019

\begin{abstract}
This study is aimed to 1) investigating the effect of marketing mix (7Ps) including product, price, place, promotion, people, physical evidence, process on purchase decision in Thiwul Ayu Mbok Sum; 2) analyzing the marketing strategy formulation at Thiwul Ayu Mbok Sum. This research used a descriptive approach. The method used in conducting this research was a case study method. However, the method applied to determine the sample was incidental sampling, about 120 people. The types and the sources of the data used were primary and secondary data. The technique of data collection used were interviews, questionnaires, and observations. Instrument of this research employed validity and reliability testing. The data analysis technique and the hypothesis testing used in this research was Structural Equation Modeling (SEM), which is the Product, Price, Promotion, Place, People, Physical Evidence as a exsogen variable and the purchase decision as a endogen variable. The results of this study indicate that 7Ps marketing strategy (product, price, place, promotion, people, physical evidence, and process) affects on purchase decision, in which the highest variable impact is the physical evidence (0.112) whereas the variable with the least impact on consumers' purchase decision is the price (0.095). Consequently, the formulations of the marketing strategy that is obtained to maintaining the spatial design in Thiwul Ayu Mbok Sum.
\end{abstract}

Keywords: marketing mix (7Ps), marketing strategy, purchase decision

\begin{abstract}
ABSTRAK
Penelitian ini bertujuan untuk 1) menganalisis pengaruh bauran pemasaran (marketing mix 7-p) yang meliputi product, price, place, promotion, people, physical evidence, procces terhadap keputusan pembelian Thiwul Ayu Mbok Sum; 2) menganalisis rumusan strategi pemasaran di Thiwul Ayu Mbok Sum. Penelitian ini menggunakan metode deskriptif. Metode pelaksanaan penelitian menggunakan metode studi kasus. Metode penentuan sampel dilakukan secara
\end{abstract}


sampling incidental yang berjumlah 120 orang. Jenis dan sumber data yang digunakan adalah data primer dan sekunder. Metode pengumpulan data yang digunakan yaitu wawancara, kuesioner dan observasi. Pengujian instrumen menggunakan uji validitas dan uji reliabilitas. Teknik analisis dan pengujian hipotesis yang digunakan adalah analisis Stuctural Equation Modeling (SEM) dengan variabel eksogen meliputi Product, Price, Promotion, Place, People, Physical Evidence, Procces, sedangkan purchase decision sebagai variabel endogen. Hasil penelitian ini menunjukkan ini bahwa bauran pemasaran $7 \mathrm{P}$ (product, price, place, promotion, people, physical evidence, procces) berpengaruh positif terhadap keputusan pembelian, dengan pengaruh tertinggi didominasi oleh variabel physical evidence dengan nilai estimate 0.112 dan pengaruh terendah adalah variabel price dengan nilai estimate 0,095. Rumusan strategi pemasaran yang didapatkan yaitu mempertahankan desain tata ruang di Thiwul Ayu Mbok Sum.

Kata kunci: bauran pemasaran, strategi pemasaran, keputusan pembelian

\section{PENDAHULUAN}

Agroindustri adalah industri yang berbahan baku utama dari produk pertanian. Studi agroindutri pada konteks ini adalah menekankan pada food processing management dalam suatu perusahaan produk olahan yang bahan baku utamanya adalah produk pertanian. Suatu industri yang menggunakan bahan baku dari pertanian dengan jumlah minimal 20\% dari jumlah bahan baku yang digunakan adalah disebut "agroindustri" (Soekartawi, 2000).

Thiwul merupakan salah satu agroindutri yang berbahan baku utama produk pertanian yaitu singkong. Thiwul menjadi salah satu makanan pokok di Indonesia pengganti nasi yang terbuat dari bahan baku gaplek. Seiring perkembangan zaman, thiwul kurang diminati masyarakat dan masyarakat lebih memilih nasi sebagai makanan pokok untuk memenuhi kebutuhan karbohidratnya. Akan tetapi, saat ini banyak pengusaha yang mengembangkan usahanya dengan kreatif dan inovatif sehingga menginovasi produk thiwul agar lebih diminati masyarakat. Dengan adanya inovasi tersebut, pengusaha dapat membuka peluang pasar baru karena pengusaha memberikan suatu hal yang menarik minat konsumen.

Thiwul Ayu Mbok Sum merupakan usaha agroindustri yang memproduksi thiwul yang berada di Dusun Mangunan, Desa Mangunan, Kecamatan Dlingo, 
Kabupaten Bantul. Disaat ketatnya persaingan industri, Thiwul Ayu Mbok Sum mampu mengembangkan usahanya dengan melakukan berbagai inovasi.

Setiap industri rumah tangga akan semakin berkembang apabila jumlah permintaan akan produk meningkat, salah satu cara untuk menyikapi hal tersebut adalah melakukan strategi pemasaran yang tepat dengan mempengaruhi keputusan pembelian konsumen untuk memaksimalkan penjualannya. Salah satu strategi untuk mempengaruhi keputusan pembelian adalah dengan menerapkan bauran pemasaran. Menurut Kotler dan Armstrong (2008) bauran pemasaran (marketing mix) adalah sekumpulan alat pemasaran taktis terkendali yang dipadukan perusahaan untuk menghasilkan respon yang diinginkannya di pasar sasaran. Bauran pemasaran terdiri dari semua hal yang dapat dilakukan perusahaan untuk mempengaruhi permintaan produknya. Berbagai kemungkinan ini dapat dikelompokkan menjadi 7 variabel, yaitu meliputi : produk (product), harga (price), saluran distribusi (place), promosi (promotion), orang (people), sarana fisik (physical envidence), dan proses (process). Ditengah persaingan yang semakin ketat perusahaan harus semakin jeli menetapkan strategi untuk memasarkan produknya ke masyarakat.

Pelaku usaha harus mempunyai strategi pemasaran yang mampu mempengaruhi keputusan pembelian yang akan berdampak kepada volume penjualan dan menghadapi ketatnya persaingan produk sejenis. Namun industri rumah tangga Thiwul Ayu Mbok Sum yang tidak paham atau tidak begitu memperhatikan strategi pemasaran tersebut, tetapi sebenarnya mereka sudah melakukan beberapa strategi hanya saja belum keseluruhan diterapkan. Dizaman sekarang thiwul kurang diminati dan kurang familiar dimata masyarakat, sehingga perlu strategi yang tepat guna menunjang usaha. Penelitian ini bertujuan untuk menganalisis pengaruh bauran pemasaran yang terdiri dari produk (product), harga (price), saluran distribusi (place), promosi (promotion), orang (people), sarana fisik (physical evidence), proses (process) terhadap keputusan pembelian dan menganalis sejauh mana penerapan strategi pemasaran di Thiwul Ayu Mbok Sum. 


\section{METODE PENELITIAN}

Metode dasar penelitian yang digunakan dalam penelitian ini adalah metode deskriptif. Metode ini digunakan untuk menjelaskan atau memberikan gambaran tentang Thiwul Ayu Mbok Sum. Metode pelaksanaan penelitian yang digunakan adalah metode studi kasus. Sebagai kasus dalam penelitian ini adalah produk Thiwul Ayu Mbok Sum memiliki rasa yang beragam, berbeda dengan produk thiwul lainnya. Yang membedakan dengan produk Thiwul Ayu Mbok Sum dengan produk yang lainnya adalah memiliki thiwul rasa pisang dan campuran coklat keju. Thiwul Ayu Mbok Sum juga menyediakan menu yang khas yaitu menyajikan thiwul rasa tawar dengan ayam kampung goreng.

Jenis dan sumber data yang digunakan ada dua, yaitu data primer dan data sekunder. Data primer diperoleh dari hasil kuesioner yang diberikan kepada responden Thiwul Ayu Mbok Sum. Sedangkan data sekunder diperoleh dari studi pustaka dan wawancara dengan pemilik Thiwul Ayu Mbok Sum. Metode pengumpulan data yang digunakan dalam penelitian ini, yaitu wawancara, kuesioner dan observasi.

Setelah data-data dikumpulkan melalui wawancara, kuesioner dan observasi perlu dilakukan pengujian instrumen dan analisis data. Pengujian instrumen dilakukan dengan uji validitas dan uji reliabilitas. Dalam penelitian ini uji validitas dilakukan dengan melakukan korelasi bivariate antara masing-masing skor indikator dengan total skor konstruk. Kuesioner dikatakan valid apabila setiap indikator menunjukkan hasil yang signifikan yaitu menggunakan $\alpha=5 \%$. Apabila nilai signifikan $<0,05$ maka kuesioner tersebut dinyatakan valid. Pengujian menggunakan software SPSS 22. Uji reliabilitas dilakukan dengan melihat nilai Cronbach Alpha, suatu konstruk atau variabel dikatakan reliabel jika memberikan nilai Cronbach Alpha $>0,70$. Pengujian ini menggunakan software SPSS 22.

Untuk melihat seberapa jauh pengaruh bauran pemasaran yang terdiri dari Product, Price, Promotion, Place, People, Physical Envidence, Process terhadap keputusan pembelian di Thiwul Ayu Mbok Sum menggunakan analisis Stuctural Equation Modeling. Structural Equation Modeling (SEM) merupakan gabungan 
dari dua metode statistik terpisah yaitu analisis faktor (factor analysis) yang dikembangkan di ilmu psikologi dan psikometri serta model persamaan simultan (simultaneous equation modeling) yang dikembangkan di ekonometrika. Pada dasarnya model persamaan struktural terdiri dari dua bagian yaitu: (1) bagian pengukuran yang menghubungkan observed variabel dengan latent variabel lewat confirmatory factor model dan (2) bagian struktur yang menghubungkan antar latent variabel lewat persamaan regresi simultan.

Instrumen penelitian yang digunakan di uji coba terlebih dahulu sebagai alat ukur untuk mengambil data penelitian agar mendapatkan instrumen yang baik dan sesuai. Maka dari itu instrumen yang di uji coba harus valid dan reliabel. Tahapan dalam pengujian hipotesis adalah dengan menentukan nilai C.R disebut juga $\mathrm{t}$-tabel dengan melihat tabel $\mathrm{t}$ untuk $\mathrm{n}=120$ dan taraf kesalahan $\alpha=5 \%$ maka didapatkan nilai t-tabel sebesar 1,981 yang digunakan untuk nilai Critical Ratio atau C.R. Nilai C.R tabel tersebut digunakan untuk dibandingkan dengan nilai C.R Hitung, nilai C.R hitung diperoleh dari hasil analisis olah data menggunakan aplikasi AMOS 24.

Kriteria Pengujian:

1. Hipotesis ditolak apabila C.R 7P Hitung kurang dari atau sama dengan 1,981 dan nilai signifikansi $\mathrm{P}$ lebih besar dari 0,05, artinya Ho diterima dan Ha ditolak.

2. Hipotesis diterima apabila C.R 7P Hitung lebih besar dari 1,981 dan nilai signifikansi P kurang dari atau sama dengan 0,05, artinya Ho ditolak dan Ha diterima.

\section{HASIL DAN PEMBAHASAN}

Bauran pemasaran adalah satu perangkat yang terdiri dari produk, harga, promosi dan distribusi, yang didalamnya akan menentukan tingkat keberhasilan pemasaran dan semua itu ditujukan untuk mendapatkan respon yang diinginkan dari pasar sasaran. Oleh karena itu bauran pemasaran dianggap sebagai salah satu unsur strategi yang paling potensial di dalam memasarkan produk (Selang, 2013; Pertiwi, 2016; Imelda, dkk., 2016). 
Ardriyanto et.al. / Jurnal Dinamika Sosial Ekonomi Vol.20 No.1, Juni 2019

Setelah masing-masing variabel laten dianalisis melalui Confirmatory Factor Analysis dan dari hasil uji tersebut ditemukan bahwa masing-masing variabel tersebut mendefinisikan variabel latennya. Maka sebuah uji Structural Equation Modeling (SEM) dari variabel eksogen (Product, Price, Promotion, Place, People, Physical Evidence, Procces) dan variabel endogen (Purchase Decision) dapat dilakukan. Dengan menggunakan AMOS 24 diperoleh hasil SEM yang ditunjukkan pada Gambar 1.

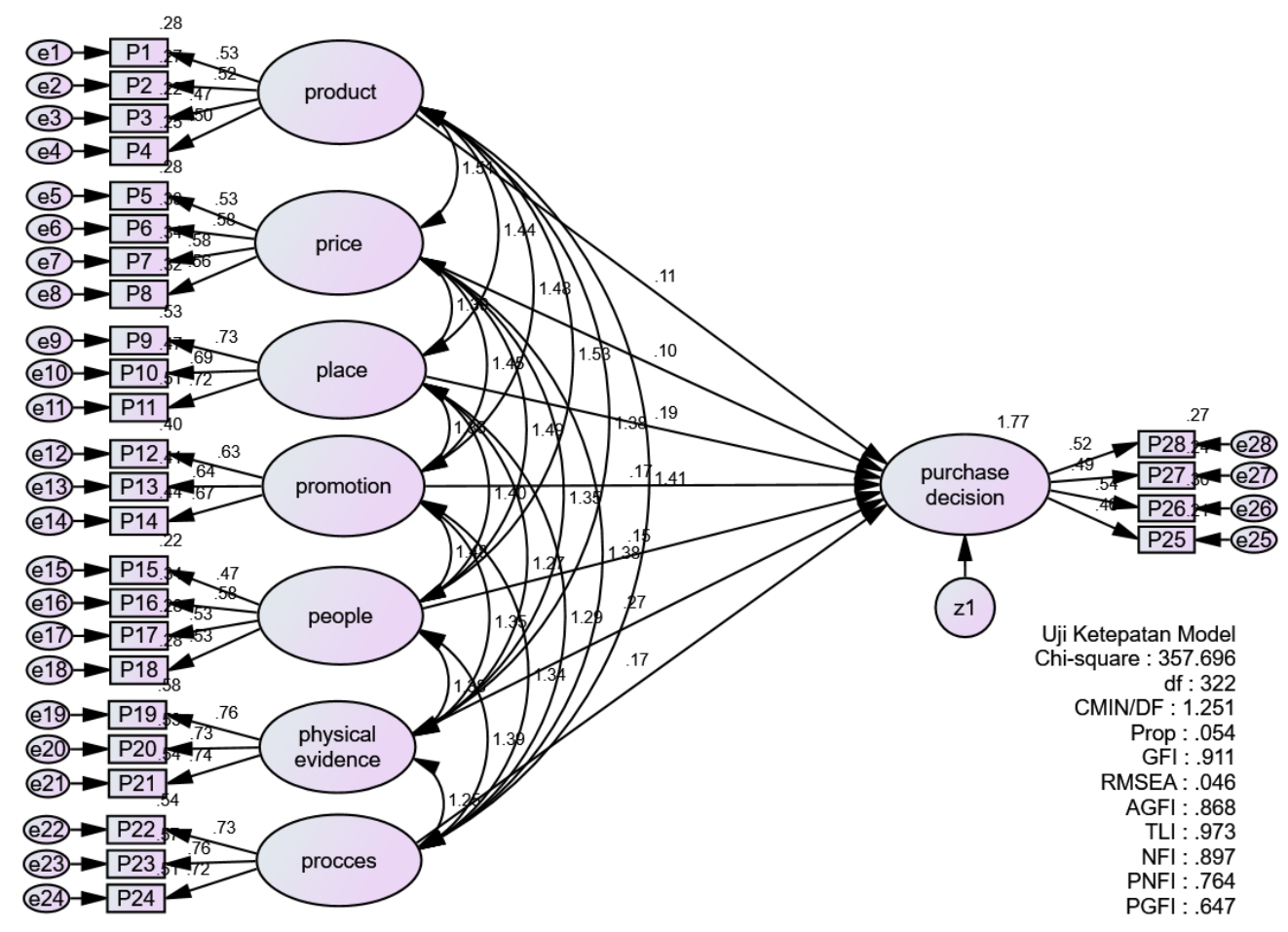

Gambar 1. Hasil Analisis Structural Equation Modeling (SEM)

Terdapat 7 faktor yang mempengaruhi bauran pemasaran yaitu Product, Price, Promotion, Place, People, Physical Evidence, Procces). Menurut Lin (2011), place merupakan lokasi pembelian yang dilakukan pelanggan. Sedangkan promosi merupakan berbagai macam cara perusahaan memberitahu pelanggannya tentang tawaran-tawaran yang diberikan. Menurut Kotler (2008), produk merupakan kombinasi barang dan jasa yang ditawarkan oleh seseorang atau lembaga untuk memenuhi kebutuhan dan keinginan pasar. Harga merupakan satusatunya unsur bauran pemasaran yang memberikan pemasukan atau pendapatan 
bagi perusahaan, di samping itu merupakan unsur bauran pemasaran bersifat fleksibel (dapat cepat diubah) (Hermawan, 2015). Strategi bauran pemasaran ditinjau dari segi harga juga mempunyai peran penting terhadap daya tarik dan kepuasaan konsumen. Harga yang terjangkau dan produk yang mempunyai kualitas juga daya tarik konsumen terhadap perusahaan (Mandasari, dkk, 2019). Dalam hal ini pengusaha dituntut mampu menghasilkan produk dengan biaya yang relatif rendah, sehingga bisa menetapkan harga yang bisa bersaing. Kendati aspek harga sangat penting, tidak dapat berdiri sendiri tanpa disokong oleh kemampuan bersaing pada aspek lain. Perusahaan perlu berpikir untuk menyenangkan konsumen. Menyenangkan ini bisa dari berbagai aspek, seperti kualitas produk yang bermutu, memberi kepuasan, sangat memperhatikan pengalaman konsumen, serta keistimewaan layanan yang unik. Berkaitan dengan layanan yang unik, perusahaan dapat memaksimalkan variabel physical evidence (Sari dan Medyani, 2018).

Saluran distribusi mempunyai peranan yang penting dalam keberlangsungan penyampaian produk dari produsen ke konsumen akhir. Pengertian saluran distribusi adalah merupakan aliran produk dari perusahaan, distributor, sampai ke pasar sehingga konsumen dapat memenuhi kebutuhan dan keinginannya (Nurseto, 2018). Menurut Kotler dan Armstrong (2008) saluran distribusi merupakan kegiatan perusahaan yang membuat produk tersedia bagi pelanggan sasaran. Oleh karena itu, didalam penetapan saluran distribusi, produsen hendaknya memperhatikan unsur-unsur yang terkait dalam bauran distribusi (distribution mix) yang terdiri dari: sistem saluran, daya jangkau, lokasi, persediaan dan transportasi. Pada dasarnya promosi adalah semua kegiatan yang bermaksud mengomunikasikan atau menyampaikan suatu produk kepada pasar sasaran untuk memberi informasi tentang keistimewaan, kegunaan dan yang paling penting adalah tentang keberadaannya, untuk mengubah sikap ataupun mendorong orang untuk bertindak (dalam hal ini membeli) (Hermawan 2015).

Menurut Hurriyati (2005) orang (people) adalah semua pelaku yang memainkan peranan dalam penyajian jasa sehingga dapat mempengaruhi persepsi pembeli. Hurriyati (2005) juga menjelaskan bahwa, sarana fisik merupakan suatu 
hal yang secara nyata turut mempengaruhi keputusan konsumen untuk membeli dan menggunakan produk jasa yang ditawarkan. Sedangkan proses adalah semua prosedur aktual, mekanisme, dan aliran aktivitas yang digunakan untuk menyampaikan jasa.

\section{Evaluasi Goodness of Fit}

Menurut Kline (2011), Prosedur SEM lebih bersifat Penegasan (confirmatory) dibandingkan dengan prosedur yang bersifat eksploratori. Analisis dengan (SEM) tidak menggambarkan kepada model yang terbentuk (koefisienkoefisien model) tetapi lebih kearah terbukti tidaknya teori-teori yang sudah kita pakai dalam membangun hipotesis di dalam kasus yang terjadi dalam penelitian. Hasil uji ketepatan model SEM ditampilkan pada Tabel 1.

Tabel 1. Evaluasi Goodness of fit Model Overall pada SEM

\begin{tabular}{cccc}
\hline Goodness of fit & Nilai Kritis & Hasil Estimasi & Keterangan \\
\hline Chi-Square & Diharapkan & 357.696 & Fit \\
& Kecil & & \\
Probability & $\geq 0,05$ & 0.054 & Fit \\
CMIN/DF & $<2$ & 1.251 & Fit \\
GFI & $\geq 0.90$ & 0.911 & Fit \\
RMSEA & $\leq 0,05$ & 0.046 & Fit \\
AGFI & $\geq 0,90$ & 0.868 & No \\
TLI & $\geq 0,90$ & 0.973 & Fit \\
NFI & $\geq 0,90$ & 0.897 & No \\
PNFI & $0.60-0.90$ & 0.764 & Fit \\
PGFI & Diharapkan & 0.647 & No \\
& tinggi & & \\
\hline
\end{tabular}

Sumber: Data primer yang diolah, 2018

Hasil uji kecocokan dari keseluruhan model dapat dilihat pada tabel 1 Menurut Wijarnako (2017) dibutuhkan minimal empat-lima kriteria uji kecocokan yang fit untuk menilai kelayakan suatu model. Berdasarkan hasil evaluasi Goodnes of fit secara overall didapatkan tujuh nilai estimasi yang fit, maka model penelitian tersebut dinyatakan fit (baik). 


\section{Evaluasi Standardized Regression Weights}

Tabel 2 Hasil Uji SEM Regression Weights Pada Setiap Indikator

\begin{tabular}{|c|c|c|c|}
\hline Item & & Variabel & Estimate \\
\hline $\mathrm{P} 4$ & $<---$ & Product & .501 \\
\hline P3 & $<---$ & Product & .500 \\
\hline $\mathrm{P} 2$ & $<---$ & Product & .521 \\
\hline $\mathrm{P} 1$ & $<---$ & Product & .530 \\
\hline P8 & $<---$ & Price & .563 \\
\hline P7 & $<---$ & Price & .579 \\
\hline P6 & $<---$ & Price & .576 \\
\hline P5 & $<---$ & Price & .534 \\
\hline P11 & $<--$ & Place & .716 \\
\hline P10 & $<---$ & Place & .685 \\
\hline P9 & $<---$ & Place & .727 \\
\hline P14 & $<---$ & Promotion & .665 \\
\hline P13 & $<---$ & Promotion & .639 \\
\hline P12 & $<---$ & Promotion & .628 \\
\hline P18 & $<---$ & People & .533 \\
\hline P17 & $<---$ & People & .531 \\
\hline P16 & $<---$ & People & .583 \\
\hline P15 & $<---$ & People & .513 \\
\hline $\mathrm{P} 21$ & $<---$ & physical_evidence & .738 \\
\hline $\mathrm{P} 20$ & $<---$ & physical_evidence & .728 \\
\hline P19 & $<---$ & physical_evidence & .763 \\
\hline P24 & $<---$ & Procces & .717 \\
\hline $\mathrm{P} 23$ & $<---$ & Procces & .757 \\
\hline $\mathrm{P} 22$ & $<---$ & Procces & .732 \\
\hline $\mathrm{P} 25$ & $<---$ & purchase_decision & .505 \\
\hline P26 & $<---$ & purchase_decision & .545 \\
\hline P27 & $<---$ & purchase_decision & .515 \\
\hline $\mathrm{P} 28$ & $<---$ & purchase_decision & .522 \\
\hline
\end{tabular}

Sumber: Data primer yang diolah, 2018

Berdasarkan Tabel 2, masing-masing indikator menunjukkan nilai pengaruh yang positif. Nilai tertinggi terdapat pada variabel physical evidence (P19) yaitu desain tata ruang di Thiwul Ayu Mbok Sum menarik. Sedangkan nilai terendah terdapat pada variabel product (P3) yaitu Thiwul Ayu Mbok Sum mempunyai variasi rasa yang beragam. 
Ardriyanto et.al. / Jurnal Dinamika Sosial Ekonomi Vol.20 No.1, Juni 2019

\section{Rumusan Strategi Pemasaran}

Berdasarkan hasil analisis yang dilakukan pada tabel 4 diperoleh nilai pengaruh disetiap variabel bauran pemasaran terhadap keputusan pembelian. Nilai pengaruh tertinggi terdapat pada variabel Physical Evidence yaitu sebesar 0,269. Variabel Physical Evidence terdiri dari tiga indikator, berdasarkan tabel 2 nilai indikator tertinggi adalah pada variabel Physical Evidence adalah pada P19 atau indikator pertama pada variabel Physical Evidence yaitu sebesar 0,763. Poin indikator P19 dalam penelitian ini adalah terkait desain tata ruang di Thiwul Ayu Mbok Sum menarik. Sehingga berdasarkan hasil tersebut dengan melihat nilai pengaruh tertinggi pada variabel dan indikator didapatkan rumusan strategi pemasaran yaitu dengan mempertahankan desain tata ruang di Thiwul Ayu Mbok Sum.

Tabel 3. Hasil Uji SEM Regression Weights : Variabel Product, Price, Place, Promotion, People, Physical Evidence, Procces, Purchase Decision

\begin{tabular}{lllrrrrl}
\hline Variabel & & Variabel & Estimate & S.E. & C.R. & P & Label \\
\hline purchase_decision & $<---$ & Product & .158 & .031 & 5.111 & $* * *$ & par_42 \\
purchase_decision & $<---$ & Price & .115 & .021 & 5.594 & $* * *$ & par_43 \\
purchase_decision & $<---$ & Place & .160 & .023 & 6.972 & $* * *$ & par_44 \\
purchase_decision & $<---$ & Promotion & .158 & .023 & 6.818 & $* * *$ & par_45 \\
purchase_decision & $<---$ & People & .234 & .039 & 6.032 & $* * *$ & par_46 \\
purchase_decision & $<---$ & physical_evid & .260 & .036 & 7.306 & $* * *$ & par_47 \\
purchase_decision & $<---$ & Procces & .160 & .024 & 6.760 & $* * *$ & par_48 \\
\hline
\end{tabular}

Sumber: Data primer yang diolah, 2018

Dalam pengujian hipotesis penelitian ini pada tabel 3 digunakan untuk melihat nilai $\mathrm{P}$ dan membandingkan nilai C.R hitung dengan nilai C.R tabel sehingga dapat diketahui apakah hipotesis diterima atau ditolak. Nilai $\mathrm{P} * * *$ pada tabel 3 menandakan bahwa signifikan pada $\alpha=5 \%$. 
Tabel 4. Hasil Uji SEM Standardized Regression Weights : Variabel Product, Price, Place, Promotion, People, Physical Evidence, Procces, Purchase Decision

\begin{tabular}{lllr}
\hline Variabel & & Variabel & Estimate \\
\hline purchase_decision & $<---$ & Product & .112 \\
purchase_decision & $<---$ & Price & .095 \\
purchase_decision & $<---$ & Place & .191 \\
purchase_decision & $<---$ & Promotion & .174 \\
purchase_decision & $<---$ & People & .149 \\
purchase_decision & $<---$ & physical_evidence & .269 \\
purchase_decision & $<---$ & Procces & .171 \\
\hline
\end{tabular}

Sumber: Data primer yang diolah, 2018

Dalam penelitian ini tabel 4 digunakan untuk melihat besarnya pengaruh variabel eksogen terhadap variabel endogen. Besarnya pengaruh dapat dilihat setelah hasil analisis sudah distandarisasi, besarnya pengaruh tersebut dapat dilihat dalam kolom estimate.

Berdasarkan tabel 3 dan tabel 4 maka hipotesis diterima, sebab berdasarkan SEM nilai C.R. masing-masing variabel melebihi nilai kritis yaitu > 1.981. selain itu nilai signifikansi $\mathrm{P}$ masing-masing variabel $<0,05$. Nilai $\mathrm{P}$ sebesar $* * *$ menandakan bahwa nilai signifikansi $\mathrm{P}$ setiap variabel mencapai $<0,05$. Hal ini membuktikan hipotesis tersebut berlaku, bahwa variabel product, price, place, promotion, people, physical evidence dan process berpengaruh terhadap variabel keputusan pembelian. Nilai pengaruh disetiap variabel potitif, dapat dilihat nilai estimate pada tabel 4 dengan data yang sudah di standarisasi.

\section{KESIMPULAN DAN SARAN}

\section{Kesimpulan}

Bauran pemasaran 7P (product, price, place, promotion, people, physical evidence, procces) berpengaruh terhadap keputusan pembelian, dengan pengaruh tertinggi didominasi oleh variabel physical evidence dan pengaruh terendah adalah variabel price. Rumusan strategi pemasaran yang didapatkan yaitu mempertahankan desain tata ruang di Thiwul Ayu Mbok Sum. 
Ardriyanto et.al. / Jurnal Dinamika Sosial Ekonomi Vol.20 No.1, Juni 2019

\section{Saran}

Sehubungan dengan nilai variabel price yang rendah maka perlu menambahkan label harga dan lebih memperjelas komposisi yang digunakan serta memperjelas identitas produk Thiwul Ayu Mbok Sum serta mempertahankan kualitas rasa Thiwul Ayu Mbok Sum yang sesuai dengan selera konsumen, yaitu dengan mempertahankan proses pembuatan thiwul yang masih tradisional yaitu menggunakan tungku bakar. Sehubungan dengan nilai variabel physical evidence yang tinggi maka disarankan untuk memperluas bangunan di Thiwul Ayu Mbok Sum agar lebih menampung jumlah pembeli karena masih adanya lahan yang dapat digunakan serta menambahkan jumlah tempat duduk bagi pembeli supaya mendapatkan tempat duduk untuk istirahat maupun menunggu pesanan.

\section{DAFTAR PUSTAKA}

Hermawan, H. (2015). Analisis Pengaruh Bauran Pemasaran terhadap Keputusan, Kepuasan dan Loyalitas Konsumen dalam Pembelian Roti Ceria di Jember. Jurnal Manajemen dan Bisnis Indonesia, 1(2), 143-161.

Hurriyati, Ratih. (2005). Bauran Pemasaran dan Loyalitas Konsumen. Bandung: Alfabeta.

Imelda, S., Huwaida, H., Rofi'i. (2016). Pengaruh Bauran Pemasaran terhadap Keputusan Mobil Toyota pada CV Sentral Motor Banjarmasin. Jurnal INTEKNA, 16(1), 69-76

Kline, R.B. (2011). Principle and Practice of Structural Equation Modeling Third Edition. New York: Guilford Press

Kotler, P dan Armstong, G. (2008). Prinsip-Prinsip Pemasaran. Jakarta: Erlangga.

Lin, S. M. 2011. Marketing Mix (7P) and Performance Assessment of West-ern Fast Food Industry in Taiwan: An Application by Associating DEMATEL and ANP. African Journal of Business Management, 5(26), 10634-10644.

Mandasari, D.J., Widodo, J., Djaja, S. (2019). Strategi pemasaran Usaha Mikro, Kecil dan Menengah (UMKM) Batik Magenda Tamanan Kabupaten Bondowoso. Jurnal Pendidikan Ekonomi: Jurnal Ilmiah Ilmu Pendidikan, Ilmu Ekonomi dan Ilmu Sosial, 13(1), 123-128.

Nurseto, S. (2018). Pengaruh Saluran Distribusi dan Promosi terhadap Kinerja Pemasaran (Studi Kasus pada UKM Furniture Kota Semarang). Jurnal Administrasi Bisnis, 7(2), 103-107.

Pertiwi, M.I., Yulianto, E., Sunarti. (2016). Pengaruh Bauran Pemasaran terhadap Keputusan Pembelian (Survei pada Konsumen Baker's King Donuts \& Coffee di MX Mall Malang). Jurnal Administrasi Bisnis, 37 (1), 179-186. 
Sari, I.P., Medyani, T.E. (2018). Harga dan Physical Evidence terhadap Kepuasan Pelanggan Warung Upnormal. Journal Sosio E-kons, 10(2), 115-120.

Selang, C.A.D. (2013). Bauran Pemasaran (Marketing Mix) Pengaruhnya terhadap Loyalitas Konsumen pada Fresh Mart Bahu Mall Manado. Jurnal EMBA, 1(3), 71-80.

Soekartawi. (2001). Pengantar Agroindustri. Jakarta: PT. Raja Grafindo Persada. Wijanarko, F. (2017). Analisis Hubungan Moda Transportasi Ojek Onlne, Ojek Pangkalan, dan Angkutan Umum Menggunakan Metode Structural Equation Modeling (SEM). Skripsi. Universitas Gadjah Mada. Yogyakarta. 